\title{
Regulatory pathway analysis of coat color genes in Mongolian horses
}

\author{
Bei Li ${ }^{1}$, Xiaolong He'2, Yiping Zhao', Dongyi Bai', Wunierfu Shiraigo ${ }^{1}$, Qinan Zhao ${ }^{1}$ and Dugarjaviin Manglai ${ }^{1 *}$
}

\begin{abstract}
Background: Studies on the molecular genetics of horse skin pigmentation have typically focused on very few genes and proteins. In this study, we used Illumina sequencing to determine the global gene expression profiles in horses with white-colored coats and those with black-colored coats, with the goal of identifying novel genes that could regulate horse coat color.

Results: Genes encoding ribosomal-associated proteins were highly expressed in horse skin. We found a total of 231 unigenes that were differentially expressed between horses with white coats and horses with black coats; 119 were down-regulated, and 112 were up-regulated. Many of the up-regulated genes in black horses, such as genes related to tyrosine metabolism, may directly regulate dark coat color. Keratin genes, MIA family genes, fatty acidrelated genes, and melanoma-associated genes were also differentially regulated, which suggests that they may play important roles in coat color formation.

Conclusions: These findings show that the transcription profiles from white and black horse skin provide useful information to understand the genetics underlying the control of skin melanin synthesis in horses, which may enhance our knowledge of human skin diseases, such as melanoma and albinism.
\end{abstract}

Keywords: Mongolian horse, RNA-Seq, Coat color, Pigmentation, Tyrosine

\section{Background}

Mammalian coat colors are determined by the quantities and distributions of melanin, which are dependent on the interaction between the genotype and the environment [1]. The most important pigments, including melanin and its derivatives, are synthesized in melanocytes by oxidation of tyrosine or tyrosine-related materials.

Mutation analyses have identified various genes that are involved in determining coat color in the horse [2]. Many of these genes regulate the expression and distribution of melanin, and their mutation can cause different phenotypes of the coat, skin, and eyes. Many of these gene mutations are situated within more than 60 loci that affect phenotype, and most are highly conserved in mammals, though the extent of their effect on pigment deposition varies [3]. Genes that commonly regulate skin and coat color in different mammalian species can be separated into 2 categories: one regulates the production, proliferation, or migration of

\footnotetext{
* Correspondence: dmanglai@163.com

${ }^{1}$ College of Animal Science, Inner Mongolia Agricultural University, Huhhot 010018, People's Republic of China

Full list of author information is available at the end of the article
}

different types of melanocytes, and the other affects pigment synthesis directly. Therefore, the formation of different skin and coat colors is determined by the regulation of genes that can change the progression/differentiation of melanocytes or the process of melanin synthesis [2].

At the cellular level, melanocytes put pigment granules into hair and skin cells; the presence and function of melanocytes therefore determine the amount, type, and character of pigmentation. Melanocytes originate along the neural crest, which also gives rise to the spinal cord and brain, and then migrate to the skin during embryogenesis [4]. The importance of this is that the pigmentary and nervous systems are closely allied in the embryo, and certain genes affect both.

Melanocytes can produce either pheomelanin or eumelanin as determined by a receptor on their surface, MC1R [5]. This receptor is activated by melanocyte-stimulating hormone, which is secreted by the pituitary gland. When activation occurs, the cells form eumelanin, while in the absence of activation, the cells form pheomelanin [6]. Whether the receptor becomes activated is determined by 2 factors: the presence or absence of melanocyte- 
stimulating hormone, and the presence or absence of cell surface receptors. Because melanocyte-stimulating hormone is consistently available to most cells in horses, regulation at the level of surface receptors is more important.

Previous studies to identify genes involved in skin pigmentation have focused on genetic polymorphisms. In the present study, we generated transcriptome profiles for horses with black or white skin utilizing highthroughput RNA deep-sequencing technology. Black and white skin from Mongolian horses was collected, and differentially expressed genes were identified by RNA-Seq, a high-throughput sequencing platform that allows for the detection and quantification of transcripts at low abundance, including novel transcript units [7]. The identification of genes for melanin production, distribution, and formation can provide a theoretical basis for the selection of skin traits during the selective breeding of horses. Additionally, increased understanding of the molecular mechanisms involved in skin pigmentation may have significance for other animals, including humans, in terms of skin-related diseases such as melanoma and albinism.

\section{Methods}

\section{Animal selection}

This investigation involved 2 Mongolian horses with black coat color (black1, black2) and 2 Mongolian horses with white coat color (white1, white2). All guidelines of the Institutional Animal Ethics Committee and the Animal Care Guidelines of the Inner Mongolia Agricultural University were followed when conducting experiments on the Mongolian horses.

\section{Feeding and management of animals}

The black and white Mongolian horses were raised under equivalent conditions. All animals had free access to the same natural pasture. The animals were provided the same feeding regime for 6 months prior to skin collection.

\section{Sampling and excision biopsy}

Skin biopsies were taken from the 4 Mongolian horses to analyze the enzymatic activity and metabolic status of melanocytes in the skin. The samples were collected in an exam room at the Inner Mongolia Agricultural University according to internal protocols and procedures. To achieve both sedation and analgesia, each animal received an intravenous bolus of $0.4 \mathrm{ml}$ of detomidine hydrochloride per $100 \mathrm{~kg}$ of body weight. The inside of the hind legs underwent a wide cleaning and disinfection. After shaving to remove the hair, an excisional biopsy was carried out, and a small area of $\leq 1 \mathrm{~cm}^{2}$ was removed and stored in a tube with a sample protector for tissues. The wound was then immediately sutured with reabsorbent closures.

\section{RNA extraction}

Total RNA was extracted using Trizol (TaKaRa) according to the manufacturer's instructions, and its purity and integrity were assessed by $1 \%$ agarose gel electrophoresis. Subsequently, genomic DNA was removed by treating the RNA sample with RNase-free DNase I for $30 \mathrm{~min}$ at $37^{\circ} \mathrm{C}$.

\section{cDNA library construction and Illumina sequencing}

To obtain poly (A) mRNA from the total RNA, oligo (dT) magnetic beads were used (Illumina). The RNA was broken down into short fragments by the addition of fragmentation buffer. These short fragments were then used as templates for first-strand cDNA synthesis with random hexamers and reverse transcriptase (Illumina). To synthesize the second strand of the cDNA, a solution of RNase $\mathrm{H}$ (Illumina), DNA polymerase I (Illumina), dNTPs, and buffer was used. The ends of the resulting double-stranded cDNA fragments were repaired, and adapters were ligated. The final version of the cDNA library was prepared from these products by purification and subsequent amplification by PCR. Using the Illumina Hiseq 2000 platform, the four prepared cDNA libraries were sequenced, resulting in 100-bp paired-end reads.

\section{Sequence preprocessing and functional annotation}

The raw sequence data was processed using a Perl script developed in our lab; it removed the adapter sequences and filtered the low-quality reads and genes with $N \geq 10 \%$. The resultant clean sequence data were mapped to the horse genome (Equus caballus) using TopHat2 without the discordant or mixed options. The reads that were uniquely mapped to the horse genome were analyzed to determine the approximate gene abundance, and gene expression levels were calculated by the reads per kilobase per million mapped (FPKM). Additionally, differentially expressed genes between the 2 Mongolian horses with black coat color and 2 Mongolian horses with white coat color were estimated by edgR using FPKM based on multiple significance tests. If $\mid \log 2$ (fold change) $\mid>1.4$ and FDR $<0.05$, then these genes were considered as differently expressed.

\section{Enrichment analysis}

The functional annotation and pathway enrichment of genes that were differentially expressed between blackand white-skinned horses were performed using the online analysis tool DAVID (DAVID 6.7: https:// david.ncifcrf.gov/tools.jsp), which is a program that manages the enriched Gene Ontology (GO) terms and 
Kyoto Encyclopedia of Genes and Genomes (KEGG) pathways that characterize genes. The differentially expressed genes (DEGs) were mapped to the GO database, and the hypergeometric test was utilized to determine which GO terms were significantly enriched among the DEGs against the background of the horse genome; GO terms were considered to be significantly enriched in the DEGs when they had corrected $p$-values $<0.05$. To determine which KEGG pathways, and therefore which complex biological behaviors, were enriched in the DEG data, a similar method was used (threshold: corrected $p$-value $<0.05)$.

\section{Quantitative real time PCR (qRT-PCR) validation}

Immediately after its removal, a piece of skin (approximately $0.5 \mathrm{~cm}^{2}$ ) was frozen in liquid nitrogen until needed for later qRT-PCR analysis. Its total RNA was obtained using Trizol (TaKaRa) according to the manufacturer's protocol. After its extraction, the total RNA was dissolved in nuclease-free water. Approximately $0.5 \mu \mathrm{g}$ of total RNA was used as a template for first-strand cDNA preparation using the PrimerScript RT reagent kit (TaKaRa) according to the manufacturer's instructions. The synthesized cDNA was diluted to $0.1 \mu \mathrm{g} / \mu \mathrm{l}$ for analysis by qRT-PCR (BioRad) using the SYBR Green Realtime PCR Master Mix (TaKaRa). The housekeeping gene GAPDH was selected as the control. To determine the relative levels of gene expression, the $2^{-\Delta \mathrm{Ct}}\left(\Delta \mathrm{Ct}=\mathrm{Ct}_{\text {target gene }}-\mathrm{Ct}_{\mathrm{GAPDH}}\right)$ method was used. ANOVA (using SAS software 9.0) was used to determine which genes were differentially expressed between black- and white-colored horse skins.

\section{Results}

\section{Assembly and functional classification of unigenes from} horse skin

A total of 24,301,563, 22,691,201, 19,423,074 and 20,465,943 pair-end reads were generated in the black1, black2, white1 and white 2 libraries, respectively, after the raw reads were filtered from the skins of white and black horses. Of the 231 known genes, 202 were marked using GO analysis. This collection of genes was sorted into 63 classes using their putative functions as a basis for categorization. The largest collection of genes was sorted entirely by general function. Additionally, we annotated the known genes utilizing GO classification analysis and sorted them into 3 groups $(74.6 \%$ were "biological processes," $11.1 \%$ were "cellular components," and 14.3\% were "molecular function") based on their presumed functions (Fig. 1).

\section{Highly expressed genes in horse skins}

The keratin-family gene latherin $(L A T H)$ was the most highly expressed gene in horse skin (Table 1). Twentyfive of the 30 most highly expressed genes encoded ribosomal proteins; Equus caballus eukaryotic translation elongation factor 1 alpha 1 (EEF1A1) and three unknown genes were also highly expressed in the horse skin.

GO enrichment analysis of in genes that are differentially expressed in black- and white-colored skins

We assessed the 202 unigenes that were differentially expressed in black and white coat color horses by GO enrichment analysis. Among 97 known genes that were classified as "biological processes," 15 genes were related to tyrosine metabolism; additionally, there were 58 known genes related to skin development. Among the 54 unigenes that were classified as "cellular components," 17 genes were related to the endoplasmic reticulum; and among 41 known "molecular function" genes, 13 genes were related to acyltransferase activity and carboxylesterase activity (Table 2).

\section{KEGG enrichment of differentially expressed genes in black and white coat color skin}

The differentially expressed genes were annotated in the KEGG database. Fourteen KEGG pathways were identified, including pathways associated with tyrosine metabolism (DCT, TAT, HPD), PPAR signaling (ME1, APOA1, $S C D, A P O A 5)$, cell adhesion (CLDN17, ITGAV, CD274, CNTN1, PDCD1LG2), and ubiquinone and terpenoidquinone biosynthesis (TAT, HPD) (Table 3).

\section{Analysis of differentially expressed genes in black and white coat color skin}

When gene expression in white- and black-colored coats was compared, we found 231 genes that were differentially expressed; 119 DEGs were down-regulated in white coat color, and 112 DEGs were up-regulated (Fig. 2). The 20 genes with the most significantly different expressions are listed in Table 4; this list shows 10 up-regulated genes and 10 down-regulated genes.

\section{Verification of differential gene expression between horse skins using quantitative real-time PCR (qRT-PCR)}

To verify the differential expression of genes in black and white coat skin, we randomly selected 18 differentially expressed genes, DCT, SLC38A4, K26, K34, K39, CLDN17, SPARC, SLC46A2, PTN, HPD, TAT, OTOR, K35, PTPLB, SLC7A8, MIA, ELOVL3 and ELOV4, to validate the expression patterns by qRT-PCR. For these 18 genes, the mRNA expression levels determined by qRT-PCR and RNA-Seq were significantly correlated (correlation coefficient $=0.825, p<0.05)$, confirming that our RNA-Seq data was highly reproducible (Fig. 3). 


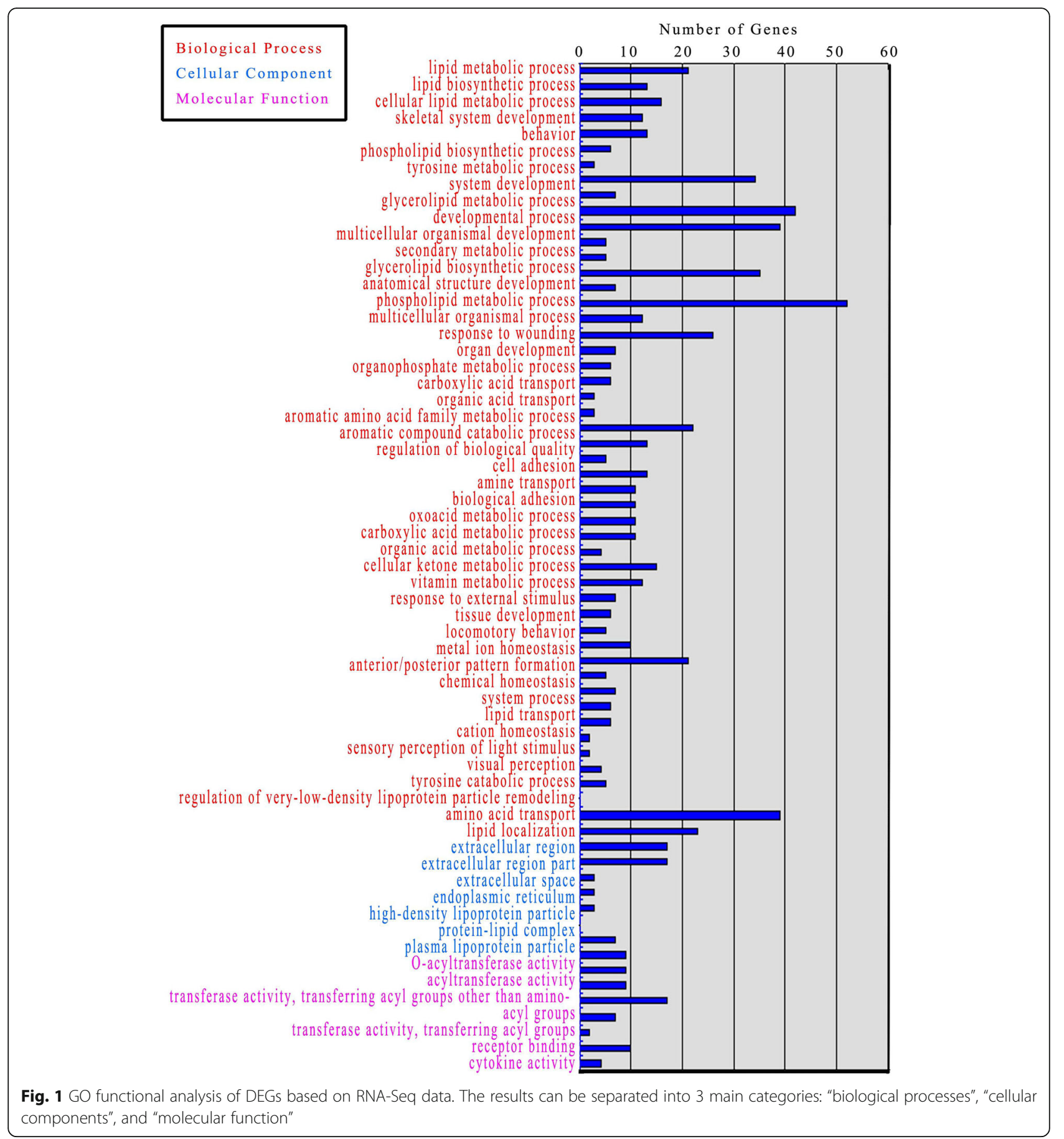

\section{Discussion}

The mechanisms of melanogenesis are intricate, and recent publications have furthered our understanding of melanin production in the skin $[8,9]$. The interactions of several basic factors, most of which are from single genetic loci, are responsible for the various colors of most horses. With the development of advanced sequencing technology, skin and coat color genetics have been well studied [10]; however, most studies have focused on gene polymorphisms, whereas the impact of gene expression on coat color has not been well characterized.

The GO and KEGG pathway analyses indicated that the vast majority of the DEGs were related to "biological processes". The pathways related to tyrosine metabolic and catabolic processes were of particular 
Table 1 The 30 genes highly expressed in horse skin

\begin{tabular}{|c|c|c|}
\hline Gene & Black coat color FPKM & White coat color FPKM \\
\hline LATH & 72,811 & 20,843 \\
\hline LOC100053601 & 27,981 & 7759 \\
\hline RPL37 & 22,692 & 15,081 \\
\hline EEF1A1 & 15,280 & 16,186 \\
\hline RPS12 & 11,689 & 10,908 \\
\hline RPS27 & 10,792 & 9377 \\
\hline RPL23A & 10,674 & 8141 \\
\hline RPL31 & 10,403 & 9728 \\
\hline RPL10 & 10,021 & 1180 \\
\hline RPL30 & 9785 & 7974 \\
\hline RPL35 & 8571 & 7940 \\
\hline RPS26 & 8320 & 7405 \\
\hline RPS3A & 8190 & 8098 \\
\hline RPL13A & 8138 & 7984 \\
\hline RPS19 & 8102 & 7883 \\
\hline RPL36A & 7815 & 1615 \\
\hline RPS25 & 7764 & 6562 \\
\hline LOC100146711 & 7500 & 6102 \\
\hline LOC100630410 & 7423 & 5754 \\
\hline RPLPO & 7281 & 7544 \\
\hline RPS20 & 7247 & 7066 \\
\hline RPS11 & 7117 & 6546 \\
\hline RPL26 & 7102 & 7405 \\
\hline RPS7 & 6983 & 6742 \\
\hline RPS23 & 6869 & 5602 \\
\hline RPS18 & 6865 & 5851 \\
\hline RPL35A & 6761 & 5431 \\
\hline RPL17 & 6699 & 6305 \\
\hline RPL39 & 6606 & 6870 \\
\hline RPL9 & 6372 & 5806 \\
\hline
\end{tabular}

interest in our dataset. Tyrosine is a non-essential amino acid responsible for melanin production via its oxidation and polymerization [11].

To confirm the Illumina results, we performed qRT-PCR for specific genes. The DCT, HPD, and TAT genes were verified to be differentially expressed in white and black horses. These genes each participate in tyrosine metabolism. Dopachrome tautomerase (DCT) catalyzes the rearrangement of dopachrome to the carboxylated derivative DHICA [12]. The results of DCT on UV DNA damage and survival pathways in human melanocytic cells were determined by knockdown tests in melanoma cells, neonatal foreskin melanoblasts in monoculture, and co-cultures with human keratinocytes $[13,14]$. DCT plays a major role in the coat color of cattle $[15,16]$ and rhesus macaques [17]. At the DCT locus, 3 mutations are known that affect pigmentation phenotypes. Guyonneau (2004) generated a knockout of the Dct gene in mice with effects restricted to pigment production and coat color [18]. As shown in Fig. 4, DCT is involved in regulating eumelanin and pheomelanin levels [19].

The Fe(II)-containing non-heme oxygenase 4-hydroxy phenylpyruvate dioxygenase (HPD) catalyzes the conversion of 4-hydroxyphenylpyruvate into homogentisate in the catabolism of tyrosine. HPD is linked to 1 of the oldest known inherited metabolic disorders, alkaptonuria, which is caused by low levels of homogentisate in the bloodstream. HPD is also directly linked to type III tyrosinemia [20]. When its concentration is low in the human body, high levels of tyrosine occur in the blood, which can cause mild mental retardation at birth and subsequent degradation in vision [21]. The liver enzyme tyrosine aminotransferase (TAT) catalyzes the transformation of tyrosine into 4-hydroxyphenylpyruvate [22]. It is the rate-limiting enzyme in the tyrosine catabolic pathway that also includes HPD [23]. Because the accumulation of tyrosine in blood causes toxic effects to tissues and organs [24], the breakdown of tyrosine by TAT is very significant for human health. Type II tyrosinemia is caused by a deficiency in TAT [25]. Thus, each of these differentially regulated genes has functions in important processes affected by tyrosine metabolism. These 3 genes were up-regulated in the tyrosine metabolism pathway in horses of black coat color, indicating that the DCT, HPD, and TAT genes affect the formation of dark coat color.

In our study, 4 keratin genes were indicated to be differentially expressed in black/white horse skin: keratin 35 was up-regulated in white coat color skin, and keratin 34 , keratin 26, and keratin 39 were up-regulated in black coat color skin. Keratinocytes generate a large number of paracrine factors that affect the growth of pigment cells and their proliferation and behavior; changes in the expression of these factors affect melanocytosis via receptor-mediated signaling pathways [26]. This result suggests that the keratin family also affects dark coat color formation.

We also identified 2 differentially expressed genes from the melanoma inhibitory activity (MIA) family: MIA and otoraplin (OTOR). MIA has been shown to have growthinhibitory activity on malignant melanoma cells in vitro $[27,28]$. MIA is expressed and secreted by melanoma cells, but not melanocytes, and its mRNA levels parallel progressive malignancy of melanocytic tumors [29, 30]. In fact, increased MIA serum levels are considered to be a reliable tumor marker in detecting and monitoring 
Table 2 GO ontology of differentially expressed genes of black and white horse skin

\begin{tabular}{|c|c|c|c|}
\hline \multirow[t]{2}{*}{ GO ontology } & \multicolumn{2}{|c|}{$\begin{array}{l}\text { Cluster } \\
\text { frequency }\end{array}$} & \multirow[t]{2}{*}{$P$ value } \\
\hline & $\mathrm{DEG}$ & $\%$ & \\
\hline \multicolumn{4}{|l|}{ Biological processes } \\
\hline Lipid metabolic process & 21 & 1.41 & 2.60E-05 \\
\hline Lipid biosynthetic process & 13 & 0.87 & 2.70E-05 \\
\hline Cellular lipid metabolic process & 16 & 1.07 & $5.74 \mathrm{E}-05$ \\
\hline Skeletal system development & 12 & 0.80 & 1.15E-04 \\
\hline Behavior & 13 & 0.87 & $8.62 \mathrm{E}-04$ \\
\hline Phospholipid biosynthetic process & 6 & 0.40 & $2.04 \mathrm{E}-03$ \\
\hline Tyrosine metabolic process & 3 & 0.20 & 2.65E-03 \\
\hline System development & 34 & 2.28 & $2.84 \mathrm{E}-03$ \\
\hline Gycerolipid metabolic process & 7 & 0.47 & $3.05 \mathrm{E}-03$ \\
\hline developmental process & 42 & 2.81 & $3.71 \mathrm{E}-03$ \\
\hline Multicellular organismal development & 39 & 2.61 & 4.03E-03 \\
\hline Secondary metabolic process & 5 & 0.33 & $5.13 \mathrm{E}-03$ \\
\hline Glycerolipid biosynthetic process & 5 & 0.33 & 5.37E-03 \\
\hline Anatomical structure development & 35 & 2.34 & $5.56 \mathrm{E}-03$ \\
\hline Phospholipid metabolic process & 7 & 0.47 & $6.62 \mathrm{E}-03$ \\
\hline Multicellular organismal process & 52 & 3.48 & $6.63 \mathrm{E}-03$ \\
\hline Response to wounding & 12 & 0.80 & 6.97E-03 \\
\hline Organ development & 26 & 1.74 & $8.40 \mathrm{E}-03$ \\
\hline Organophosphate metabolic process & 7 & 0.47 & $8.42 \mathrm{E}-03$ \\
\hline Carboxylic acid transport & 6 & 0.40 & 9.57E-03 \\
\hline Organic acid transport & 6 & 0.40 & $9.84 \mathrm{E}-03$ \\
\hline Aromatic amino acid family metabolic process & 3 & 0.20 & 0.0119 \\
\hline Aromatic compound catabolic process & 3 & 0.20 & 0.0131 \\
\hline Regulation of biological quality & 22 & 1.47 & 0.0169 \\
\hline Cell adhesion & 13 & 0.87 & 0.0201 \\
\hline Amine transport & 5 & 0.33 & 0.0202 \\
\hline Biological adhesion & 13 & 0.87 & 0.0203 \\
\hline Oxoacid metabolic process & 11 & 0.74 & 0.0246 \\
\hline Carboxylic acid metabolic process & 11 & 0.74 & 0.0246 \\
\hline Organic acid metabolic process & 11 & 0.74 & 0.0257 \\
\hline Cellular ketone metabolic process & 11 & 0.74 & 0.0276 \\
\hline Vitamin metabolic process & 4 & 0.27 & 0.0282 \\
\hline Response to external stimulus & 15 & 1.00 & 0.0300 \\
\hline Tissue development & 12 & 0.80 & 0.0321 \\
\hline Locomotory behavior & 7 & 0.47 & 0.0339 \\
\hline Metal ion homeostasis & 6 & 0.40 & 0.0346 \\
\hline Anterior/posterior pattern formation & 5 & 0.33 & 0.0349 \\
\hline Chemical homeostasis & 10 & 0.67 & 0.0365 \\
\hline System process & 21 & 1.41 & 0.0384 \\
\hline Lipid transport & 5 & 0.33 & 0.0389 \\
\hline Cation homeostasis & 7 & 0.47 & 0.0404 \\
\hline
\end{tabular}

Table 2 GO ontology of differentially expressed genes of black and white horse skin (Continued)

\begin{tabular}{|c|c|c|c|}
\hline \multirow[t]{2}{*}{ GO ontology } & \multicolumn{2}{|c|}{$\begin{array}{l}\text { Cluster } \\
\text { frequency }\end{array}$} & \multirow[t]{2}{*}{$P$ value } \\
\hline & $\overline{D E G}$ & $\%$ & \\
\hline Sensory perception of light stimulus & 6 & 0.40 & 0.0418 \\
\hline Visual perception & 6 & 0.40 & 0.0418 \\
\hline Tyrosine catabolic process & 2 & 0.13 & 0.0431 \\
\hline $\begin{array}{l}\text { Regulation of very-low-density } \\
\text { lipoprotein particle remodeling }\end{array}$ & 2 & 0.13 & 0.0431 \\
\hline Amino acid transport & 4 & 0.27 & 0.0448 \\
\hline Lipid localization & 5 & 0.33 & 0.0496 \\
\hline \multicolumn{4}{|l|}{ Cellular component } \\
\hline Extracellular region & 39 & 2.61 & $8.82 \mathrm{E}-07$ \\
\hline Extracellular region part & 23 & 1.54 & $1.63 \mathrm{E}-05$ \\
\hline Extracellular space & 17 & 1.14 & $2.10 \mathrm{E}-04$ \\
\hline Endoplasmic reticulum & 17 & 1.14 & $6.86 \mathrm{E}-03$ \\
\hline High-density lipoprotein particle & 3 & 0.20 & 0.0186 \\
\hline Protein-lipid complex & 3 & 0.20 & 0.0350 \\
\hline Plasma lipoprotein particle & 3 & 0.20 & 0.0350 \\
\hline \multicolumn{4}{|l|}{ Molecular function } \\
\hline O-acyltransferase activity & 7 & 0.47 & 7.67E-07 \\
\hline Acyltransferase activity & 9 & 0.60 & $2.76 \mathrm{E}-04$ \\
\hline $\begin{array}{l}\text { Transferase activity, transferring acyl } \\
\text { groups other than amino-acyl groups }\end{array}$ & 9 & 0.60 & $2.95 \mathrm{E}-04$ \\
\hline Transferase activity, transferring acyl groups & 9 & 0.60 & 3.83E-04 \\
\hline Receptor binding & 17 & 1.14 & $2.77 \mathrm{E}-03$ \\
\hline Cytokine activity & 7 & 0.47 & $5.80 \mathrm{E}-03$ \\
\hline Hemoglobin binding & 2 & 0.13 & 0.0248 \\
\hline Protein dimerization activity & 10 & 0.67 & 0.0371 \\
\hline Carboxylesterase activity & 4 & 0.27 & 0.0460 \\
\hline
\end{tabular}

$\%=$ DGE/BGDGE $\times 100 \%$; DEG represents the number of differentially expressed genes annotated to each GO ontology. BGDEG represents the number of all background differentially expressed genes annotated to each $\mathrm{GO}$ ontology

metastatic disease and responses to therapy [31, 32]. OTOR is secreted via the Golgi apparatus and may function in cartilage development and maintenance. A frequent polymorphism in the translation start codon of this gene, potentially associated with alternative polyA sites, is associated with forms of deafness [33]. Gray horses are at an increased risk for melanoma, with $70-80 \%$ over the age of 15 presenting with melanomas [34]. It is possible that melanoma in light coat color horses is associated with the expression of MIA family genes.

Other genes identified as differentially expressed in our study include PTN, RGS13, and SPARC. The secreted heparin-binding protein pleiotrophin (PTN) 
Table 3 Enriched pathways of differentially expressed genes in black and white skin

\begin{tabular}{lllrr}
\hline Pathways & $\begin{array}{l}\text { Differentially } \\
\text { expressed genes }^{\text {a }}\end{array}$ & KEGG unigenes $^{\text {b }}$ & P value & Pathway ID \\
\hline PPAR signaling pathway & 4 & 69 & 0.023 & hsa03320 \\
Cell adhesion molecules & 5 & 143 & 0.028 & hsa04514 \\
Tyrosine metabolism & 3 & 38 & 0.057 & hsa00350 \\
Ubiquinone and other terpenoid-quinone biosynthesis & 2 & 11 & 0.060 & hsa00130 \\
\hline
\end{tabular}

${ }^{a}$ Differentially expressed genes in each pathway in the KEGG database

${ }^{\mathrm{b}}$ Gene numbers in this pathway in the KEGG database

has been shown to be involved in cell growth and differentiation [35]. Not much is known about the effects of PTN on skin pigmentation and melanocyte function. Transfection studies, however, have shown that PTN decreases melanogenesis through MITF degradation via Erk1/2 activation [36]. In vitro, the chemotaxis of B cells is controlled by the regulator of G-protein signaling 13 (RGS13); this control is thought to be carried out by increasing the GTPase activity of $G_{\alpha}$ proteins that are coupled to chemokine receptors [37]. RGS13 expression also reduces cAMP production [38], which plays an important role in melanoma even though genetic alterations in components of this pathway are not commonly found in melanomas $[39,40]$. The incorporation of collagen into the skin is controlled by secreted protein acidic and rich in cysteine (SPARC) (or osteonectin or BM-40) [41]. SPARC has various roles that it carries out in cooperation with

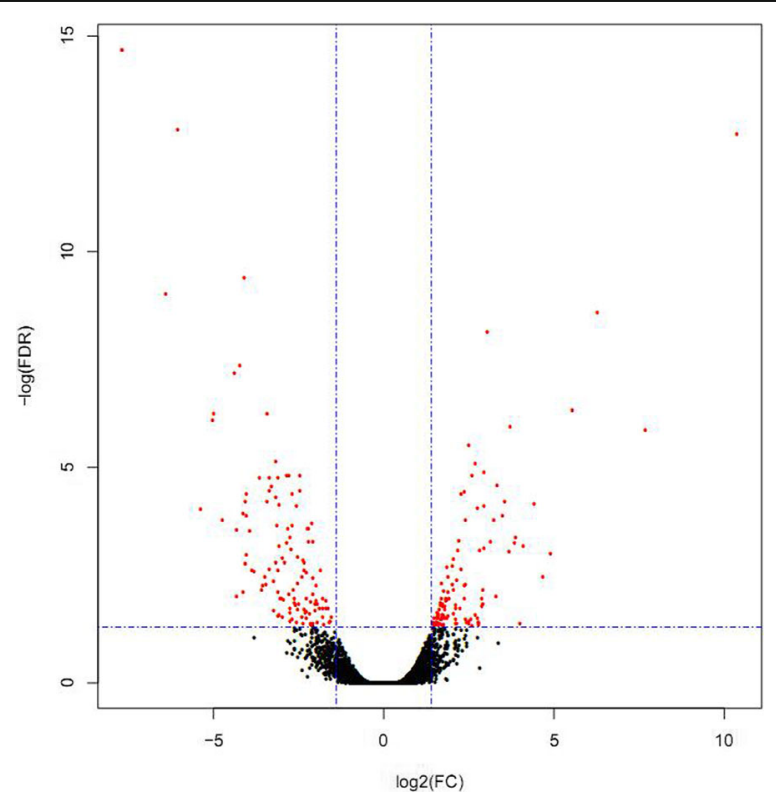

Fig. 2 Comparison between gene expression levels of black and white horse skin libraries. The $X$ and $Y$-axes show the mRNA expression levels in the 4 samples. The up-regulated and down-regulated genes are represented in red and black many extracellular matrix units: it behaves as a de-adhesive molecule, regulates cytokine and growth factor activities, and inhibits the cell cycle [42]. SPARC has also been shown to be strongly expressed in advanced primary and metastatic melanomas [43]. Although the molecular events responsible for their activity remain to be defined, the upregulation of PTN, RGS13, and SPARC in black color skin

Table 4 The top 10 up-regulated and down-regulated differentially expressed genes in white coat color vs. black coat color

\begin{tabular}{|c|c|c|c|}
\hline Gene & $\begin{array}{l}\log _{2} \text { (White } \\
\text { FPKM/Black FPKM) }\end{array}$ & UP/DOWN & Function \\
\hline MHCB3 & 10.379 & up & $\begin{array}{l}\text { MHC class I protein } \\
\text { complex }\end{array}$ \\
\hline CALCB & 5.537 & up & hormone activity \\
\hline CPSF4L & 4.888 & up & metal ion binding \\
\hline LOC100057688 & 4.685 & up & protein binding \\
\hline UNKNOW & 3.833 & up & $\begin{array}{l}\text { oxidoreductase activity, } \\
\text { acting on paired donors, } \\
\text { with incorporation or } \\
\text { reduction of molecular } \\
\text { oxygen, reduced flavin } \\
\text { or flavoprotein as } 1 \text { donor, } \\
\text { and incorporation of } 1 \\
\text { atom of oxygen }\end{array}$ \\
\hline LOC100054146 & 3.707 & up & nucleosome assembly \\
\hline FOSB & 3.674 & up & $\begin{array}{l}\text { sequence-specific DNA } \\
\text { binding }\end{array}$ \\
\hline CACNB4 & 3.548 & up & protein binding \\
\hline UNKNOW & 3.506 & up & protein binding \\
\hline CHODL & 3.327 & up & carbohydrate binding \\
\hline CPNE6 & -7.670 & down & protein binding \\
\hline UNKNOW & -6.393 & down & protein binding \\
\hline LOC100629895 & -6.058 & down & mammaglobin-A-like \\
\hline UNKNOW & -5.387 & down & protein binding \\
\hline C1QTNF6 & -5.038 & down & collagen trimer \\
\hline NALCN & -4.743 & down & cation channel activity \\
\hline LOC100061216 & -4.383 & down & $\begin{array}{l}\text { integral component of } \\
\text { membrane }\end{array}$ \\
\hline $\mathrm{HBB}$ & -4.327 & down & oxygen transport \\
\hline OTOR & -4.318 & down & protein binding \\
\hline UNKNOW & -4.229 & down & keratin filament \\
\hline
\end{tabular}




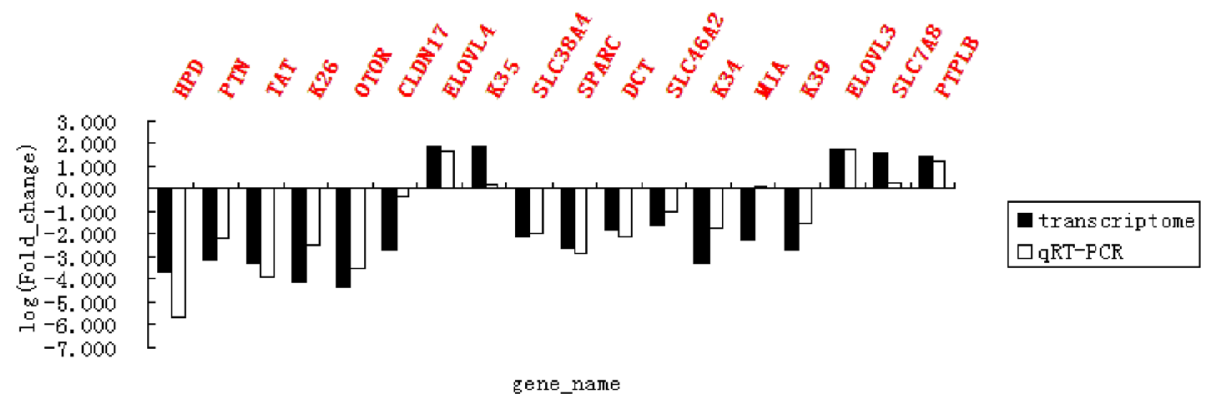

Fig. 3 qRT-PCR validation of DEGs characterized by RNA-Seq. The results verify the differential expression of genes in black and white coat color skin, which is consistent with the RNA-Seq findings

could explain the incidence of melanoma in light coat color horses.

True white horses of the kind used in this study have the dominant-negative W allele of the KIT gene [44, 45]. KIT encodes stem cell factor (steel factor) that is involved in stem cell differentiation and subsequent melanocytic migration [46]. Failure of melanocyte migration results in white markings on horses, including all-white coats. We did not find any differences in gene expression of KIT in the present study, though this could be due to the small sample size. However, similar global gene expression profiling of black and white sheep skin using Illumina sequencing [47] and transcriptome profiling of black and white rabbits [48] also did not find differential expression of KIT. Similar to our results, these studies did find up-regulated genes related to tyrosine metabolism and melanogenesis, including DCT in sheep, as well as keratin family genes. Zhang and coworkers [49] cataloged global gene expression profiles in Lueyang chickens with white versus black skin by Illumina 2000 sequencing, and found differential expression of KIT. They also discovered upregulation of tyrosine metabolism genes in black skinned chickens, but not changes in the expression of keratin family members. Overall, these results and those of the present study indicate that while there are many common differences in gene expression between white and black skinned vertebrates, they also vary considerably by species. More work is needed to determine the specific factors involved and their mechanisms.

\section{Conclusion}

In this study, differentially expressed genes in horses with white and black coat colors were screened using high-throughput sequencing. The genes identified in this study may affect the formation of horse coat color directly or indirectly. Although the genes controlling horse coat color formation are not completely known, the transcription analysis presented in this study provides valuable information. For the first time, we present a collection of genes that are differentially expressed in horse skins of different colors. Some genes have not been described previously, and others are known, but they are likely to be involved in skin pigmentation and other physiological functions. The description of these differentially expressed genes will allow further study of the molecular regulation of horse coat color.

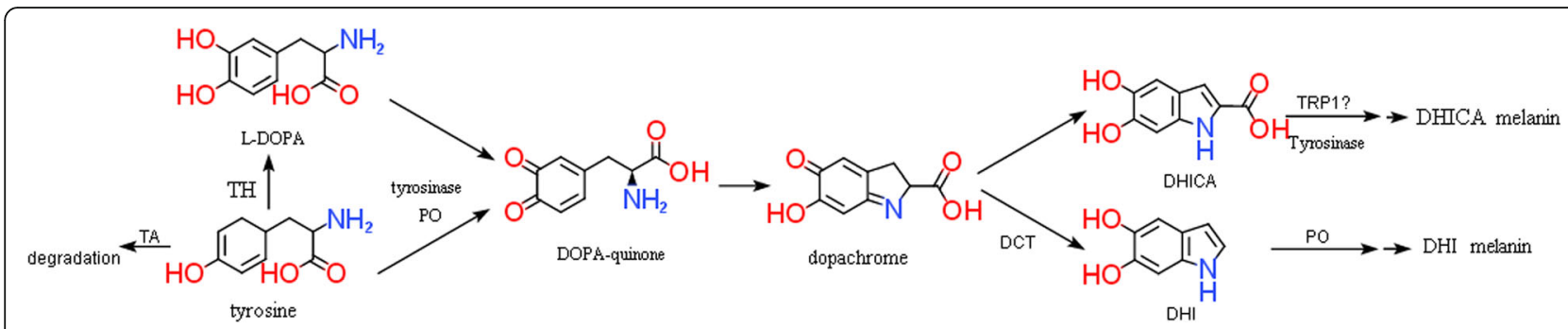

Fig. 4 Common pathways of melanin synthesis in animals. Enzymes are abbreviated as follows: tyrosine aminotransferase, TA; tyrosine hydroxylase, TH; phenoloxidase, PO; dopachrome tautomerase, DCT; tyrosinase-related protein 1, TRP1; 5,6-dihydroxyindole, DHI; 5,6-dihydroxyindole-2-carboxylic acid, DHICA 


\section{Funding}

This work was supported by the National Natural Science Foundation of China (31360538, 31472070), Natural Science Foundation of Inner Mongolia (2015BS0314, 2017ZD06), Inner Mongolia key laboratory project (20130902) and Engineering Research Center of Horse Science and Industry of Inner Mongolia (201603002)

\section{Availability of data and materials}

We have provided detailed information about materials and method in our manuscript, so we will not provide data and supporting materials in this section.

\section{Authors' contributions}

$\mathrm{BL}$ and $\mathrm{XH}$ conceived the research. QZ and DB collected the skin of Mongolian horses. BL, YZ, and XH performed RNA extraction, cDNA library construction, and Illumina sequencing. WS carried out sequence preprocessing and functional annotation, BL carried out qRT-PCR validation. BL and DM wrote the paper. All authors read and approved the final manuscript.

\section{Ethics approval}

All animal experiments were conducted in accordance with the Institutional Animal Ethics Committee and Animal Care Guidelines of the Inner Mongolia Agricultural University, which governed the use of experimental animals.

\section{Consent for publication}

Not applicable.

\section{Competing interests}

The authors declare that they have no competing interests.

\section{Publisher's Note}

Springer Nature remains neutral with regard to jurisdictional claims in published maps and institutional affiliations.

\section{Author details}

College of Animal Science, Inner Mongolia Agricultural University, Huhhot 010018, People's Republic of China. ${ }^{2}$ Inner Mongolia Academy of Agricultural and Animal Husbandry Sciences, Huhhot 010031, People's Republic of China.

\section{Received: 27 February 2017 Accepted: 18 September 2017}

\section{Published online: 29 September 2017}

\section{Reference}

1. Sturm RA, Teasdale RD, Box NF. Human pigmentation genes: Identification, structure and consequences of polymor-phic variation. Gene. 2001;277:4962

2. Rieder S, Taourit S, Mariat D, Langlois B, Guérin G. Mutations in the agouti (ASIP), the extension (MC1R), and the brown (TYRP1) loci and their association to coat color phenotypes in horses (Equus caballus). Mamm Genome. 2001;12(6):450-5.

3. Thiruvenkadan AK, Kandasamy N, Panneerselvam S. Coat colour inheritance in horse. Livest Sci. 2008;117(2):109-29.

4. Cichorek M, Wachulska M, Stasiewicz A, Tymińska A. Skin melanocytes: biology and development. Adv Dermatol Allergol. 2013;1:30-41.

5. Beaumont KA, Shekar SL, Newton RA, James MR, Stow JL, Duffy DL, Sturm RA. Receptor function, dominant negative activity and phenotype correlations for MC1R variant alleles. Hum Mol Genet. 2007:16(18):2249-60.

6. Marklund L, Moller MJ, Sandberg K, Andersson L. A missense mutation in the gene for melanocyte-stimulating hormone receptor (MC1R) is associated with the chestnut coat color in horses. Mamm Genome. 1996; 7(12):895-9

7. Ozsolak F, Milos PM. RNA sequencing: advances, challenges and opportunities. Nat Rev Genet. 2011;12(2):87-98.

8. Plonka PM, Passeron T, Brenner M, Tobin DJ, Shibahara S, Thomas A, Slominski A, Kadekaro AL, Hershkovitz D, Peters E, Nordlund JJ. What are melanocytes really doing all day long...? Exp Dermatol. 2009;18(9):799-819.

9. Slominski A, Tobin DJ, Shibahara S, Wortsman J. Melanin pigmentation in mammalian skin and its hormonal regulation. Physiol Rev. 2004;84(4):1155228
10. Rouzaud F, Oulmouden A, Kos L. The untranslated side of hair and skin mammalian pigmentation: Beyond coding sequences. IUBMB Life. 2010; 62(5):340-6

11. D'Mello SA, Finlay GJ, Baguley BC, Askarian-Amiri ME: Signaling Pathways in Melanogenesis. Int J Mol Sci. 2016;17(7):pii:E1144.

12. Villareal MO, Kume S, Bourhim T, Bakhtaoui FZ, Kashiwagi K, Han J, Gadhi C, Isoda H. Activation of MITF by Argan Oil Leads to the Inhibition of the Tyrosinase and Dopachrome Tautomerase Expressions in B16 Murine Melanoma Cells. Evid Based Complement Alternat Med. 2013;340107. 1-9.

13. Tsukamoto K, Jackson IJ, Urabe K, Montague PM, Hearing VJ. A second tyrosinase-related protein, TRP-2, is a melanogenic enzyme termed DOPAchrome tautomerase. EMBO J. 1992;11(2):519-26.

14. Ainger SA, Yong XL, Wong SS, Skalamera D, Gabrielli B, Leonard JH, Sturm RA. DCT protects human melanocytic cells from UVR and ROS damage and increases cell viability. Exp Dermatol. 2014:23(12):916-21.

15. Mohanty TR, Seo KS, Park KM, Choi TJ, Choe HS, Baik DH, Hwang $H_{\text {. }}$ Molecular variation in pigmentation genes contributing to coat colour in native Korean Hanwoo cattle. Anim Genet. 2008;39(5):550-3.

16. Guibert S, Girardot M, Leveziel H, Julien R, Oulmouden A. Pheomelanin coat colour dilution in French cattle breeds is not correlated with the TYR, TYRP1 and DCT transcription levels. Pigment Cell Res. 2004;17(4):337-45.

17. Bradley BJ, Gerald MS, Widdig A, Mundy NI. Coat Color Variation and Pigmentation Gene Expression in Rhesus Macaques (Macaca mulatta). J Mamm Evol. 2013;20(3):263-70.

18. Guyonneau L, Murisier F, Rossier A, Moulin A, Beermann F. Melanocytes and pigmentation are affected in dopachrome tautomerase knockout mice. Mol Cell Biol. 2004;24(8):3396-403.

19. Vavricka CJ, Han Q, Mehere P, Ding H, Christensen BM, Li J. Tyrosine metabolic enzymes from insects and mammals: A comparative perspective. Insect Sci. 2014:21(1):13-9.

20. Tomoeda K, Awata H, Matsuura T, Matsuda I, Ploechl E, Milovac T, Boneh A, Scott CR, Danks DM, Endo F. Mutations in the 4-hydroxyphenylpyruvic acid dioxygenase gene are responsible for tyrosinemia type III and hawkinsinuria. Mol Genet Metab. 2000;71(3):506-10.

21. Hühn R, Stoermer H, Klingele B, Bausch E, Fois A, Farnetani M, Di Rocco M, Boué J, Kirk JM, Coleman R, Scherer G. Novel and recurrent tyrosine aminotransferase gene mutations in tyrosinemia type II. Hum Genet. 1998;102(3):305-13.

22. JB D. Tyrosine aminotransferase: a transaminase among others? Cellular and molecular biology. Cellular and molecular biology. 1992;38(2):95-114.

23. Rettenmeier $\mathrm{R}$, Natt $\mathrm{E}$, Zentgraf $\mathrm{H}$, Scherer $\mathrm{G}$. Isolation and characterization of the human tyrosine aminotransferase gene. Nucleic Acids Res. 1990; 18(13):3853-61.

24. Wilhelm B LJ. RNA-Seq quantitative measurement of expression through massively parallel RNA-sequencing. Methods. 2009;48(249-257).

25. Dickson AJ, Marston FA, Pogson Cl. Tyrosine aminotransferase as the ratelimiting step for tyrosine catabolism in isolated rat liver cells. FEBS Lett. 1981:127(1):28-32

26. Bogdahn U, Apfel R, Hahn M, Gerlach M, Behl C, Hoppe J, Martin R. Autocrine tumor cell growth-inhibiting activities from human malignant melanoma. Cancer Res. 1989;49(19):5358-63.

27. Apfel R, Lottspeich F, Hoppe J, Behl C, Dürr G, Bogdahn U. Purification and analysis of growth regulating proteins secreted by a human melanoma cell line. Melanoma Res. 1992:2(5-6):327-36.

28. Bosserhoff AK, Hein R, Bogdahn U, Buettner R. Structure and promoter analysis of the gene encoding the human melanoma-inhibiting protein MIA. J Biol Chem. 1996;271(1):490-5.

29. van Groningen JJ, Bloemers HP, Swart GW. Identification of melanoma inhibitory activity and other differentially expressed messenger RNAs in human melanoma cell lines with different metastatic capacity by messenger RNA differential display. Cancer Res. 1995;55(24):6237-43.

30. Schmidt J, Bosserhoff AK. Processing of MIA protein during melanoma cell migration. Int J Cancer. 2009:125(7):1587-94.

31. Schmidt J, Riechers A, Stoll R, Amann T, Fink F, Spruss T, Gronwald W, König B, Hellerbrand C, Bosserhoff AK. Targeting melanoma metastasis and immunosuppression with a new mode of melanoma inhibitory activity (MIA) protein inhibition. PLoS One. 2012;7(5):e37941.

32. Odashiro M, Hans Filho G, Pereira PR, Castro AR, Stief AC, Pontes ER, Odashiro AN. Melanoma inhibitory activity in Brazilian patients with cutaneous melanoma. An Bras Dermatol. 2015;90(3):327-32.

33. Robertson NG, Heller S, Lin JS, Resendes BL, Weremowicz S, Denis CS, Bell AM, Hudspeth AJ, Morton CC. A novel conserved cochlear gene, OTOR: 
identification, expression analysis, and chromosomal mapping. Genomics. 2000;66(3):242-8.

34. Pielberg GR, Golovko A, Sundström E, Curik I, Lennartsson J, Seltenhammer MH, Druml T, Binns M, Fitzsimmons C, Lindgren G, Sandberg K. A cis-acting regulatory mutation causes premature hair graying and susceptibility to melanoma in the horse. Nat Genet. 2008;40(8):1004-9.

35. Deuel TF, Zhang N, Yeh HJ, Silos-Santiago I, Wang ZY. Pleiotrophin: a cytokine with diverse functions and a novel signaling pathway. Arch Biochem Biophys. 2002;397(2):162-71.

36. Choi WJ, Kim M, Park JY, Park TJ, Kang HY. Pleiotrophin inhibits melanogenesis via Erk1/2-MITF signaling in normal human melanocytes. Pigment Cell Melanoma Res. 2015;28(1):51-60.

37. Shi GX, Harrison K, Wilson GL, Moratz C, Kehrl JH. RGS13 regulates germinal center B lymphocytes responsiveness to CXC chemokine ligand (CXCL)12 and CXCL13. J Immunol. 2002:169(5):2507-15.

38. Johnson EN, Druey KM. Functional characterization of the $\mathrm{G}$ protein regulator RGS13. J Biol Chem. 2002;277(19):16768-74.

39. Otreba M RJ, Buszman E, Wrzesniok D: Regulation of melanogenesis: the role of CAMP and MITF. Postepy Hig Med Dosw (Online).2012;66:33-40.

40. Rodríguez Cl, Setaluri V. Cyclic AMP (CAMP) signaling in melanocytes and melanoma. Arch Biochem Biophys. 2014;563:22-7.

41. Rentz TJ, Poobalarahi F, Bornstein P, Sage EH, Bradshaw AD. SPARC regulates processing of procollagen I and collagen fibrillogenesis in dermal fibroblasts. J Biol Chem. 2007;282(30):22062-71.

42. AD B. Diverse biological functions of the SPARC family of proteins. Int J Biochem Cell Biol. 2012:44(3):480-8.

43. Ledda MF, Adris S, Bravo Al, Kairiyama C, Bover L, Chernajovsky Y, Mordoh J, Podhajcer OL. Suppression of SPARC expression by antisense RNA abrogates the tumorigenicity of human melanoma cells. Nat Med. 1997;3(2):171-6.

44. Haase B, Brooks SA, Schlumbaum A, Azor PJ, Bailey E, Alaeddine F, Mevissen M, Burger D, Poncet PA, Rieder S, Leeb T. Allelic heterogeneity at the equine KIT locus in dominant white (W) horses. PLoS Genet. 2007;3(11):2101-8.

45. Bai DY, Yang LH, Unerhu U, Zhao YP, Zhao QN, Hasigaowa H, Dugarjaviin M. Effects of Kit gene on coat depigmentation in white horses. Yi Chuan. 2011; 33(11):1171-8

46. Rönnstrand L. Signal transduction via the stem cell factor receptor/c-Kit. Cell Mol Life Sci. 2004;61(19-20):2535-48.

47. Fan R, Xie J, Bai J, Wang H, Tian X, Bai R, Jia X, Yang L, Song Y, Herrid M, Gao W. Skin transcriptome profiles associated with coat color in sheep. BMC Genomics. 2013;14:389.

48. Qin LZ WW, Shi LJ, Wan XY, Yan XR, Weng QQ, Wu XS: Transcriptome expression profiling of fur color formation in domestic rabbits using Solexa sequencing. Genet Mol Res 2016, 15(2).1-16.

49. Zhang J, Liu F, Cao J, Liu X. Skin transcriptome profiles associated with skin color in chickens. PLoS One. 2015;10(6):e0127301.

\section{Submit your next manuscript to BioMed Central and we will help you at every step:}

- We accept pre-submission inquiries

- Our selector tool helps you to find the most relevant journal

- We provide round the clock customer support

- Convenient online submission

- Thorough peer review

- Inclusion in PubMed and all major indexing services

- Maximum visibility for your research

Submit your manuscript at www.biomedcentral.com/submit

C) Biomed Central 